\title{
Contextualism, Moral Disagreement, and Proposition Clouds
}

\author{
Jussi Suikkanen
}

Final author copy; to be published in the Oxford Studies in Metaethics.

\section{Introduction}

I understand Contextualism to be the following semantic framework for understanding the meaning of moral terms. ${ }^{1}$ Consider the sentence 'eating meat is wrong'. According to Contextualism, this sentence does not have truth-conditional content because '... is wrong' is not a predicate that has a fixed property as its semantic value. Rather, on this view, its meaning consists merely of a 'character' which can be understood as a function from contexts of use to fixed contents (Kaplan 1989). ${ }^{2}$ Contextualism thus claims that, due to what the predicate means, only in a context of use '... is wrong' will have a specific property as its semantic value - the context plays an ineliminable role in determining what that property is.

There are two familiar versions of Contextualism according to which the characters of moral predicates contain an essential indexical element. ${ }^{3}$ According to these views, the contexts on which the characters of moral predicates operate include moral codes that are accepted by either the speaker (indexically, from the speaker's perspective, my moral system) or her moral community (our moral system). Thus, according to the subjectivist

\footnotetext{
${ }^{1}$ My formulation of Contextualism is inspired by Björnsson and Finlay (2010: 7-8), Brogaard (2008: 385-386 and 400), Dreier (1990: 8, 1999, and 2009: 79-81), and Wong (1984: Ch. 5).

${ }^{2}$ Character represents what one must understand in order to grasp the meaning of the term whereas the truth-evaluable content is what an expression says (Dreier 2009: 81).

${ }^{3}$ Historically, these views are more often understood as versions of subjectivism and relativism. See Montaigne (1958 [1572-1574]), Hobbes (2012 [1651]), Sumner (1906), and Harman (1975). 'Character' here refers to the Kaplanian characters defined above: the functions from contexts of use to fixed properties as semantic values.
} 
versions of Contextualism (hereafter the SC-views), when I utter the sentence 'eating meat is wrong', in this context the utterance ascribes a certain natural property $\mathrm{N}_{1}$ (say that of not maximizing the amount of happiness) to eating meat because my moral code - as an essential element of the context - is against actions that are $\mathrm{N}_{1}$. Likewise, when you utter that same sentence, your utterance ascribes a different natural property $\mathrm{N}_{2}$ to eating meat because your moral code - as an essential element of your context - is against actions that are $\mathrm{N}_{2}$. Thus, on this view, the character of '... is wrong' is a function from contexts of use - essentially consisting of the speakers' moral codes to certain natural properties determined those codes.

Relativist versions of contextualism (hereafter the RCviews) work in a similar way except here the moral code that determines the semantic value of '... is wrong' in a context is not the speaker's personal code but rather the code of her moral community. Thus, according to RCviews, when I utter the sentence 'eating meat is wrong' that utterance will ascribe a certain natural property to actions of eating meat because the moral code internalized by the majority of people in my moral community is against the actions that have that property.

Both subjectivist and relativist versions of Contextualism (hereafter the SRC-views) have important theoretical advantages. These views do not require positing any mysterious non-natural properties and yet they are able to rely on the standard truth-conditional, compositional semantics in explaining the meaning of more complex moral sentences. These views furthermore promise to solve many epistemic challenges facing other metaethical views and even help us to give an account of the internal connection between moral judgments and motivation. ${ }^{4}$

However, because there are many compelling objections to the SRC-views, until quite recently most metaethicists have taken these views to be merely good for philosophical target practice. Yet, more recently, several metaethicists have tried to develop the SRC-views in ways

\footnotetext{
${ }^{4}$ For the latter advantage, see Dreier (1990); for the former, see Capps, Lynch and Massey (2009).
} 
that could enable these views to avoid the standard objections to them (see footnote 1). This chapter takes part in that project by focusing on two objections. \$2 first explains how the SRC-views seem unable to accommodate intuitive moral disagreements. It also considers how these views seem to lead to an unfortunate form of arbitrariness because we live in multicultural societies.

This chapter then argues that these two problems can be solved together: the second problem provides a solution to the first one. $\S 3$ first explains how the popular Kratzerstyled contextualist accounts of epistemic modals suffer from a corresponding disagreement problem. It also outlines how Kai von Fintel and Anthony Gillies (2011) rely on proposition clouds to address that challenge. $\S 4$ then develops a similar response to the disagreement objection to the SRC-views by relying on an insight extracted from the arbitrariness objection.

The basic idea is that, given that we live in multicultural societies, the contexts in which we utter moral sentences fail to provide unique truth-evaluable contents for our moral assertions. When we make moral utterances, we can hence only put into play proposition clouds. Furthermore, because our moral discourse has a fundamental action coordinating function, we, as audience members, should react with disagreement to those propositions in the relevant clouds the rejection of which will best enable us to co-ordinate choices and actions. $\S 5$ finally concludes by outlining this proposal's advantages over its main rivals.

\section{Disagreement and Arbitrariness}

Consider the following exchange:

(1) Ann: It is not wrong to eat meat.

(2) Ben: No, eating meat is wrong!

When Ann and Ben utter (1) and (2), they intuitively disagree. The fundamental problem with the SRC-views is that they cannot guarantee this. Let's stipulate that Ann and Ben have internalized different moral codes. In this case, the SC-views entail that according to Ann's utterance eating meat lacks a certain natural property whereas according to Ben eating meat has a different natural 
property. In this situation, Ann and Ben would not be disagreeing but rather talking past one another - their claims could, after all, be both true at the same time. ${ }^{5}$ The RC-views do enable Ann and Ben to disagree when they belong to the same moral community. ${ }^{6}$ However, if Ann and Ben belong to different moral communities with different moral codes, these views again make them talk about different natural properties of actions.

Consider also the following response from Ben (Björnsson and Finlay 2010: 19):

(3) Ben: \#When you utter the sentence 'eating meat is not wrong', what you say is true. Nevertheless, eating meat is wrong.

This response makes no sense and yet the SRC-views seem to make it appropriate. On these views, what Ann asserts when she utters (1) is that eating meat does not have the relevant natural property determined by her moral code. According to the SRC-views, by uttering the first part of (3), Ben could agree that it is true that eating meat lacks that property. By uttering the second part of (3), he could then claim that eating meat is still wrong (i.e., eating meat has the natural property which his moral code picks out as salient). But, given that (3) makes no sense, the SRC-views arguably fail (see also §5 below).

The second arbitrariness objection first observes that it is a philosophical myth that, in every area, there is a single moral community such that every person in that area is a member of that moral community and it only (ShaferLandau 2004: Ch. 10). ${ }^{7}$ Instead our societies are multicultural and we belong to many moral communities simultaneously. Consider Shafer-Landau's (2004: 44) reallife example in which, years ago in France, a young

\footnotetext{
${ }^{5}$ This objection was introduced by Moore (1912: Ch. 3) and Hare (1952: 148-149). Since them, it has become ubiquitous.

${ }^{6}$ See, for example, Shafer-Landau (2010: 286).

7 Shafer-Landau (2004: Ch. 8) calls a different objection to the SRCviews the arbitrariness objection. According to this objection, the concerns on which the moral standards are based cannot be supported by reasons in the SRC-framework and hence they must be arbitrary. For a response, see Blackburn (1998).
} 
woman was about to be forced to undergo a clitoridectomy by her family. She was, fortunately, able to escape and she even won a lawsuit against her family.

Consider then the young woman's utterance 'What they are doing to me is wrong!'. According to the SRC-views, in order to know whether this utterance is true, we must first know which moral code the context of the utterance picks out as the one that determines which natural property her assertion ascribes to clitoridectomy. The problem is that the utterance is made in a context in which several different communities are salient. Given that the young woman identified herself as a member of the French society, we might think that the code relevant in the context is the conventional French morality. Yet, the young woman also belonged to the Algerian immigrant community. Thus, the relevant moral code in the context could equally well be this community's code. The problem is that, whichever community's moral code is salient, that code determines which natural property the previous assertion ascribes to clitoridectomy and therefore also whether the assertion is true. If the French moral code is salient, then the young woman's assertion is true whereas, if the Algerian immigrant culture's code is salient, then that assertion might turn out to be false.

In response, the defenders of the SRC-views could try to stipulate that the characters of moral predicates are such that they uniquely pick out a certain kind of communities and codes as salient in every context. The idea could be that, given the meaning the moral terms have, it is always the larger society whose moral code is salient. Or, perhaps it is always the smaller, more tight-knit community. Or, perhaps we should let the speaker herself to choose which moral community and code is relevant. The fundamental problem with all these solutions is arbitrariness. As Shafer-Landau (2004: 46) points out, whether what the woman's family was trying to do was wrong is a substantial moral question. It seems objectionable that such a question could be solved merely by considering whether the character of moral terms is such that the larger community's moral code is always salient (or the 
smaller community's or...). That would be solving a substantial moral problem on arbitrary semantic grounds.

\section{Epistemic Modals, Disagreement, and Proposition Clouds}

This chapter responds to the previous objections by drawing from the recent debates concerning epistemic modals. ${ }^{8}$ The following two utterances are examples of how modal terms can be used in an 'epistemic flavour' (i.e., as epistemic modals):

(4) Ed: My keys might be in the car.

(5) Fred: Your keys must be in the car.

The standard semantic model for understanding these statements was developed by Angelika Kratzer (1977, 1981 and 1991) on the basis of David Lewis's (1973) seminal work. It is known as the Lewis-Kratzer Semantics or the Standard Ordering Semantics.

According to this model, epistemic modals are propositional operators. The propositions that embed within their scope (in (4) and (5), the proposition that Ed's keys are in the car) are called 'prejacents'. The semantic role of these operators is then to quantify over a certain contextually determined set of worlds. The strict necessity modal 'must' functions as a universal quantifier whereas the weak possibility modal 'may' functions as an existential quantifier. Must (p) is thus true when $p$ is true in all the relevant worlds whereas May $(p)$ is true when $p$ is true in some of those worlds.

The model then claims that the context of use determines in two stages the relevant sets of worlds over which the epistemic modals quantify. The context first picks out a 'modal base', which consists of all the worlds that are consistent with a body of information that has certain properties salient in the conversational context (such as being what the speaker knows, for example). The conversational context then also provides an ordering source that ranks the worlds in the modal base with a certain standard. In the case of epistemic modals, this

\footnotetext{
${ }^{8}$ For representative essays, see Egan and Weatherson (2011).
} 
ordering source is based on what is stereotypical. The worlds in the modal base are ranked in terms of how well they match with what is the normal course of events relative to the conversational background. Must (p) is then true when $p$ is the case in all the highest ranked worlds in the modal base whereas May (p) is true when $p$ is true in some of them.

The Standard Ordering Semantics too faces a disagreement objection (von Fintel and Gillies 2011: 114117). Imagine that $\mathrm{Ed}$ and Greg are trying to find Ed's keys. Ed utters (4) and Greg responds:

(6) Greg: No, they cannot be in the car. You still had them when we came in.

Here Ed and Greg disagree about whether Ed's keys might be in the car. When we apply the standard model, we must first consider which informational state is salient in the context as that state determines which worlds belong to the modal base. One alternative is to think that, in any context of use, what the speaker knows always constitutes the relevant information state. Yet, this assumption would make Ed and Greg talk past one another. Ed would claiming that in some of the worlds compatible with what he knows the keys are in the car, but Greg could not reject that proposition by claiming that the keys are not in the car in the worlds compatible with what he knows.

The information states that are salient in the relevant contexts cannot therefore be what the speakers know as individuals. The alternative is then to think that, when $\mathrm{Ed}$ utters (4), he is claiming that the keys are in the car in some of the worlds compatible with the aggregate of what he and Greg know. Given that it is possible to understand Greg's claim to be about the fact that the keys are not in the car in those same worlds, this view can make Ed and Greg disagree.

This proposal, however, leads to a different problem. Given how little we usually know about what others know, the previous response to the disagreement problem makes it mysterious how we could ever use epistemic modals to make warranted assertions. If Ed does not know 
what Greg knows about the keys, he cannot be justified to assert that the keys are in the car in the worlds that are compatible with his own and Greg's knowledge. Yet, surely, we often are justified to use epistemic modals even when we know little about what others know.

Kai von Fintel and Anthony Gillies (2011: 117-129) provide an ingenious solution to the previous dilemma. ${ }^{9}$ They first observe that many contexts fail to 'successfully resolve all indeterminacies and ambiguities' (von Fintel and Gillies 2011: 117). Imagine that you are at a conference where a stranger wants to know where you are from. In this type of cases, there are often not enough contextual cues that would help you to interpret what the stranger is asking (von Fintel and Gillies 2011: 118). Does she want to know where you were born, where you grew up, where you did your PhD, where you work, or what? The context is just too sparse to resolve the ambiguity in question.

Von Fintel and Gillies suggest that, similarly, when Ed uses the epistemic modal 'might' in (4), the context leaves it open the knowledge of which group constitutes the information state that generates the modal base. The conclusion they draw is that utterances of epistemic modals take 'place against a cloud of admissible contexts one for each resolution of the relevant group that is compatible with the facts as they are' when the utterance is made (ibid.). They thus believe that, when we use epistemic modals, the best we can do is to put into play a proposition cloud. Each proposition put into play corresponds to the prejacent being true in either all or some of the worlds (depending on the epistemic modal) that are compatible with a body of information that is an aggregate of what a different group knows.

For the audience, all the propositions put into play are then available for rejection and acceptance. In the previous example, by uttering (4), Ed puts into play at least two propositions: (i) that the keys are in the car at least in some of the worlds compatible with what he knows and (ii) that they are in the car in some of the worlds compatible with what he and Greg know in aggregate. In order to be

${ }^{9}$ For objections, see, e.g., MacFarlane (2010). 
justified to put into play these propositions, Ed must be justified to assert at least one of them. In this case, that proposition naturally is the one according to which the keys are in the car in the worlds compatible with what he knows (von Fintel and Gillies 2011: 120). In order to put the relevant propositions into play, he thus need not be justified to assert the other proposition the content of which also depends on what Greg knows. This avoids the second horn of the dilemma above.

To which propositions put into play by Ed should Greg then react? Von Fintel and Gillies (2011: 121) claim that, given the general standard norms of conversation, this is determined by the denial or acceptance of which proposition would make a suitably informative contribution to the conversation given its purpose. When Ed puts the previous propositions into play, he is asserting the proposition that the keys are in the car in the worlds compatible with what he knows and, in a way, simultaneously asking Greg whether the other proposition is true too. Knowing whether (ii) is also true would, after all, be informative given that this would enable Ed to know whether the keys are in the car in the more restricted set of worlds also compatible with whatever additional evidence Greg has. Knowing whether those propositions are true would hence help Ed to find his keys, which is the purpose of the conversation.

In order to make an informative contribution, Greg should therefore either confirm or reject the proposition (ii). This proposition is something Greg will have a reasonable opinion on assuming that he has some idea of what he knows about the location of the keys. If part of what Greg knows is that Ed came in with them, then he can justifiably rule out that the keys are in the car in the worlds compatible with what he and Ed know in aggregate. As a consequence, we can understand the utterances (4) and (6) to express a genuine first-order factual disagreement. Ed puts into a play a cloud of propositions by uttering (4) and by uttering (6) Greg denies that some of those very propositions are true. The disagreement between Ed and Greg can thus be 
understood in the traditional way as one person asserting and the other rejecting the very same proposition.

The next section investigates whether the previous account can provide a new response to the disagreement objection to the SRC-views in metaethics. Before that, one further observation is needed. It has been argued that the truth of moral utterances is information-sensitive (Prichard 1932), which suggests that moral concepts contain an element of epistemic modality. Consider the miners case in which a group of ten miners are trapped in one of two shafts (Kolodny and MacFarlane 2010). We do not know in which shafts the miners are and rising waters threaten their lives. We have time to block only one shaft if we block the wrong one everyone dies whereas if we block neither shaft only one miner dies.

Many have the intuition that it would be wrong to block a shaft because doing so risks nine additional lives. It has then been suggested that, when we say that it would be wrong to block a shaft, we mean that in all the worlds both (i) compatible with what we know and (ii) ranked highest by morality we do not block a shaft. ${ }^{10}$ This interpretation applies the Standard Ordering Semantics to moral expressions by assuming that (i) what is morally best provides the relevant ordering source and (ii) what we know provides the epistemic modal base of the worlds that are ordered. The latter feature of the proposal means that this view builds epistemic modality into the semantics of 'wrong'.

This proposal enables us to apply the previous idea of proposition clouds directly to some moral disagreements. Consider the following conversation between Charles who

\footnotetext{
10 The Standard Ordering Semantics itself is problematic here. Of the worlds that are compatible with what we know, many ordering sources would rank blocking A first in the worlds in which the miners are in A and blocking B first in the rest of the worlds. According to the Standard Ordering Semantics, this entails that it would not be wrong to block a shaft. For this reason, it has been suggested that we additionally need to rely on information-sensitive ordering sources that rank the relevant worlds in the epistemic modal base in terms of expected value (Dowell 2013; Silk 2013). For an objection, see Finlay (2016: 186-187).
} 
does not know where the miners are and David who knows they are in A:

(7) Charles: It would be wrong to block a shaft.

(8) David: No, we are definitely required to block shaft $\mathrm{A}$ - the miners are in there.

In the current framework, Charles's utterance puts into play a cloud of propositions because the context fails to determine a unique group whose aggregated knowledge generates the epistemic modal base for the evaluation of the truth of (7). ${ }^{11}$ Thus, according to one proposition Charles puts into play, neither shaft is blocked in the worlds that morality ranks highest of those that are compatible with what he knows. ${ }^{12}$ Similarly, according to another proposition he puts into play, neither shaft is blocked in the worlds that morality ranks highest of the worlds compatible with what he and David know in aggregate. David's utterance (8) should then be interpreted as making an informative contribution to the conversation. Given that his evidence rules out the worlds in which the miners are in $B$, he can react with rejection to the proposition according to which no shaft is blocked in the worlds that are ranked highest by morality of the worlds that are compatible with what he and Charles know in aggregate. This contribution is highly informative because rejecting those propositions helps Charles to save all the miners. ${ }^{13}$

Thus, insofar as the truth of moral assertions is information-sensitive and epistemic modality is built into the semantics of moral terms, already the previous account of epistemic modals in its original form helps us to make sense of some moral disagreements in the

\footnotetext{
${ }^{11}$ According to Dowell (2013), Charles's own referential intentions are sufficient to determine which proposition he asserts. It's not clear, however, how Charles's audience could access those intentions so as to know to which proposition they are to react.

12 We only get this consequence if the ordering source provided by morality is itself information-sensitive. See footnote 9 above.

${ }^{13}$ On this view, moral utterances made by informed agents can often play an instrumental role in helping the agents to choose the most moral course of action. This does not entail, however, that the agents' interest in morality needs to be merely instrumental.
} 
contextualist framework. In this form, however, the view only helps us to accommodate moral disagreements between people who share the same moral principles but have different amounts of empirical information. Charles and David do not really disagree about whether it is right to save people but rather David only disagrees with Charles because he knows the location of the miners and thus is in a position to help save more lives.

Yet, when Ann and Ben disagree when they utter (1) and (2), they can be in a context in which they know all the same empirical facts and they also know that they know the same facts. Because of this, their disagreement cannot be explained with the idea that one of them has some additional empirical information and thus is in a position to rule out additional worlds from the modal base. Rather, their disagreement is a more fundamental moral disagreement about what is right based on accepting different moral codes. The idea that speakers put different moral propositions into play with their moral utterances because epistemic modals are built into the meaning of moral terms cannot thus explain what is going on in these more fundamental moral disagreements. This is why the next section develops a contextualist account of disagreements that could be applied more broadly also to the more fundamental moral disagreements. ${ }^{14}$

\section{Moral Disagreement and Proposition Clouds}

My proposal begins from an observation concerning the traditional forms of relativism in metaethics: these views classified moral communities in a maximally coarsegrained way. They assumed that we all belong to just one moral community. The idea was that, within the borders of a state, the citizens of that state always form the relevant moral community whose moral standards determine which actions are right and wrong within that

\footnotetext{
${ }^{14}$ For reasons of space, the proposal below will not include epistemic information-sensitivity within the contextualist semantics of moral terms. The proposal is, however, fully compatible with adding that aspect of the character of moral terms to the account. For SRC-views formulated explicitly in that way, see Björnsson and Finlay (2010) and Dowell (2013).
} 
state. In some cases, the relevant moral community was assumed to be an even larger unit: the Western moral community, the Asian moral community, or the like. These views just did not seem to recognise any smaller moral communities.

Shafer-Landau's (2004: Ch. 10) arbitrariness objection shows that these assumptions are untenable. He is surely right in pointing out that, in addition to the large national moral communities, there are also many smaller moral communities (such as the Algerian immigrant community in France) to which many of us belong. When we recognise these smaller moral communities and the fact that we can belong to many of them simultaneously, there is no reason why we could not classify moral communities in a more fine-grained way. We could think, plausibly enough, that there exists a plenitude of overlapping moral communities so that we all belong to a vast number of different ones. Some of these moral communities are formed by people who live in the same area (the Europeans, the Brits, the Brummies, etc.), whereas others are formed through class membership, age, general interests, shared political views, immigration, ethnicity, profession, Facebook groups, and the like. We can even stipulate that, whatever relation ties a certain group of individuals together, these individuals thereby form a moral community.

Let us then return to the original disagreement. According to the RC-views, when Ann utters (1), given the character of 'wrong' and the context of use, her utterance asserts that the actions of eating meat lack a certain natural property determined by the moral code of her community. The immediate problem is that, as we have just seen, Ann belongs to a number of different moral communities and so there is no such thing as her unique moral community. Furthermore, if the context of utterance is an ordinary conversational context, it is hard to see what contextual cues would suffice to help Ann's audience to interpret against the moral code of which community the truth of her utterance should be evaluated. The context in question will help to rule out some moral communities as irrelevant. Given the constraints provided by charity, 
presumably she cannot be talking about the type of actions that are forbidden by the moral code of the majority of the group consisting of herself, the oldest citizen of Iceland, and the fastest runner in Switzerland. Yet, even so, the context seems too poor to be able to disambiguate between all the things she could reasonably be interpreted to mean.

The natural idea is then to think that, as a consequence, the best Ann can do by uttering (1) is to put into play a cloud of all the propositions that are not ruled out by the contextual cues as reasonable interpretations. Each one of these propositions asserts that the action of eating meat lacks a different natural property because the content of each proposition in the cloud is determined by a different moral community's moral code. Ann is justified to put into play this proposition cloud if she is in a position to assert at least one of the propositions in it. Given that Ann herself already forms a moral community of one person, Ann must at least be justified to put into play the relevant proposition cloud. She has to be in a position to assert that eating meat lacks a certain natural property determined by her own personal moral code.

To which proposition put into play by Ann should Ben then react? Above, it was suggested that the response to this question is provided by the general Gricean norms of conversation. Grice (1975: 45-46) suggested that the Cooperative Principle that captures what we can be expected to do in a conversation contains two maxims of quantity. We are to make our conversational contributions as informative as is required by the purposes of the conversation (we should not say too little) and we should also not make our contributions more informative than required by those purposes (we should not say too much). To which proposition should Ben then react so as to make his conversational contribution appropriately informative?

Grice's own formulation of the maxim of quantity answers this question. In order to evaluate the informativeness of a conversational contribution, we must first consider the purpose of the conversation in question. In the example concerning Ed's keys, the purpose was to find Ed's keys. This is why it was sufficiently informative for Greg to 
reject the propositions according to which the keys are in the car in the worlds that are compatible with what he knows. After all, ruling those worlds out was enough to enable Ed to find his keys. This means that, in order to find out to which propositions it would be appropriate for Ben to react, we need to consider the fundamental purpose of moral conversations.

Here I will rely on a widely held assumption according to which one fundamental purpose of moral discourse is to co-ordinate choice and action in a mutually beneficial manner. ${ }^{15}$ The starting point of this assumption is that, because we all have a vast number of different needs and desires and we live in circumstances in which resources are not unrestrictedly abundant, there are bound to be conflicts between us concerning resource allocation. ${ }^{16}$ Yet, if such conflicts were frequent and escalated into violence, our lives would be in Hobbes's (2012 [1651]: Pt. 1, Ch. 13, para. 9) words 'solitary, poor, nasty, brutish, and short'.

My assumption will be that one raison d'être of moral discourse and thought is to help us to avoid the previous type of escalating vicious conflicts. ${ }^{17}$ When individuals share a moral code (including its action-guiding principles and the corresponding reactive attitudes towards norm violations), they are able to avoid the previous kind of conflicts and their escalation in a way that also enables mutually beneficial co-operation. Because the adoption of a moral code requires certain practical attitudes, the individuals who adopt a shared moral code will thus come to have a more co-operative and altruistic stance towards interaction. They will constrain the selfish pursuit of their own interests so as to comply with the shared code, which prevents harm to others. They will also have

\footnotetext{
15 This assumption thus grants that moral discourse generally serves an instrumental purpose. This again need not entail that the individuals who take part in the discourse are similarly motivated by instrumental reasons.

${ }^{16}$ In John Rawls's (1971: §22) words, we thus live in the 'circumstances of justice'.

17 In fact, it can be argued that moral thought and talk evolved in human beings because of their ability to co-ordinate the actions of communities in a way that was an evolutionary advantage (Joyce 2006: Ch. 4).
} 
certain shared expectations concerning the execution of contracts and the distribution of the benefits of social cooperation. All these shared attitudes then mean fewer conflicts and more of the kinds of social interaction that benefit everyone. Shared moral standards also prevent the escalation of conflicts by co-ordinating third parties to side with one of the two parties in a conflict and thus by putting social pressure on the parties in the conflict to solve their conflict peacefully. ${ }^{18}$

In the following, I thus assume that one important purpose of moral conversations is that having such conversations serves the fundamental action co-ordinating function of the moral discourse. Through moral conversations we can put pressure on the choices and actions of others in a way that is required for meeting our 'competing needs in a social, cooperative setting' (Blackburn 1993: 168). This assumption then helps us to answer the question of to which of the propositions put into play by Ann Ben should react so as to make his contribution suitably informative. I propose that, in the context of moral conversations, we should understand the informativeness of conversational contributions in terms of the contribution's ability to co-ordinate behaviour in a way that serves the fundamental action co-ordinating purpose of the moral discourse.

Recall that, when Ann utters (1), she puts into play a proposition cloud. According to every proposition in this cloud, the actions of eating meat lack a certain natural property determined by the moral codes of different moral communities. Hence, when Ben disagrees with Ann by uttering (2), he must be rejecting at least one of these propositions. By uttering (2), he must be asserting that eating meat actually has at least one of the salient natural properties determined the moral codes of the relevant moral communities. ${ }^{19}$

\footnotetext{
18 See DeScioli and Kurzban (2012).

19 In Finlay's (2017: 188-190) terminology, my strategy to accommodate intuitive moral disagreements is 'content-based' rather than non-content-based (see §5 below).
} 
Above, I acknowledged that there exists a plenitude of different moral communities. Yet, the mere fact that certain moral communities are against the type of actions to which eating meat belongs will put very little pressure on Ann's actions. For example, Ann will not be moved by the fact that the majority of those people who, like her, were born at $4.24 \mathrm{am}$ are against certain type of actions. ${ }^{20}$

Firstly, it can well be that, even if most of those people are against the actions of the type in question, Ann does not belong to the majority in this respect. This means that the mere fact that a moral community to which she belongs is against eating meat need not in itself provide an internal reason for her not to eat meat - the kind of reason that would motivate her in practical reasoning that begins from her own cares and concerns. ${ }^{21}$ Secondly, Ann need not identify strongly with the other members of this group. She does not need to think that who she really is as a person is in someway dependant on being a member of this group. Finally, the members of this group also seem too unconnected to one another so as to be able to coordinate their reactive attitudes and actions in a way that would be required for putting social pressure on the choices and actions of the other members of the group.

For these reasons, if Ben were to reject the proposition according to which actions of eating meat do not have a certain natural property determined by the moral code of the majority of people born at $4.24 \mathrm{am}$ are, this would not be an appropriately informative contribution to his conversation with Ann. It would not be sufficiently informative because it would fail to serve the fundamental action co-ordinating function of the moral discourse.

The previous example also helps us see to which propositions Ben should react so as to make an

\footnotetext{
${ }^{20}$ Because it is so obvious that no agent will be moved by this fact, the proposition that this community is not against eating meat did probably not belong to the proposition cloud put into play by Ann. The contextual cues present in all contexts should be sufficient for Ben to know that this could have been what Ann meant. I am merely using the example for illustrative purposes to provide a contrast to the communities that matter.

${ }^{21}$ See Williams (1979).
} 
informative, action co-ordinating contribution. Ann also belongs to at least some moral communities such that:

i. she shares the same core cares and concerns that are reflected in the moral code that is accepted by the majority of the community's members,

ii. she considers her own personal identity to be at least in part grounded in being a member of the community, and

iii. the community in question is sufficiently close-knit both to be able to put significant social pressure on the choices and actions of its members and to be able to effectively side with one party in conflict cases.

According to at least some of the propositions put into play by Ann, eating meat lacks a natural property determined by what types of actions are opposed by the previous special kind of moral communities of which Ann is a member. If Ben can reject these propositions (i.e., if he is in a position to assert that in fact eating meat has those very natural properties), then presumably this will put pressure on Ann's actions in a way that can co-ordinate her and Ben's behaviour. This is why rejecting those propositions would be informative (assuming that we understand the informativeness of moral utterances in terms of the moral discourse's fundamental action coordinating purpose). As a consequence, we know to which propositions Ben should react in the cloud put into play by Ann: to those that put significant pressure on Ann's choices and actions. These are the propositions in which the semantic value of '... is wrong' is determined by the moral codes of those moral communities that have the features i.-iii. introduced above.

Let me finish by making few further observations. Firstly, even if I have described to which propositions Ben should react, this does not mean that he will respond to those propositions. Ben can fail to make an informative, action co-ordinating contribution. He can, for example, react to the proposition according to which eating meat does not have a certain natural property determined by his own 
personal moral code. ${ }^{22}$ Yet, rejecting this proposition will have only a limited effect on Ann's behaviour - it will move her only to the extend that she cares about her relationship to Ben.

How can Ann know to which proposition Ben is actually reacting? Ben's own utterance (2) itself is not very helpful in this respect - it will not enable Ann to understand what Ben means. After all, just like Ann's own utterance, it too can only put into play a proposition cloud. There are, however, two methods that Ann can use to hone in on the meaning of Ben's response. Firstly, she too has internalized the same conversational maxims that she should assume guide Ben's conversational contributions. Thus, she can initially assume that Ben is reacting to the propositions that matter in terms of co-ordination. As a consequence, she is warranted to assume that Ben is talking about the natural properties that are determined by the moral codes of the communities that are important to her are..$^{23}$

Secondly, moral conversations rarely consist only of a short exchange of blunt utterances such as (1) and (2). Rather, the conversations that start in this way usually continue with a game of giving and receiving reasons. Ben would presumably next talk about the considerations that he thinks make eating meat wrong - he might argue that

${ }^{22}$ Assuming that this proposition was one of the propositions put into play by Ann, in this case Ben would still be disagreeing with her. It's just that his disagreeing contribution to their conversation would not be very informative.

${ }^{23}$ One potential objection at this point concerns disagreement cases in which the participants share no common cares, concerns, or moral standards. Imagine a disagreement case like this between a vegan and a carnivore, where the participants are also members of distinct vegan and carnivore communities. In this case, it might be argued that these individuals could not disagree according to my proposal because these individuals do not belong to the same communities that could co-ordinate their actions effectively. Here I want to suggest that one of the propositions in the cloud put into play by the vegan could be that the use of animal products has a certain natural property determined by the moral code accepted by the majority of the mankind. The carnivore could then reject at least this proposition. This contribution to the conversation would, of course, be only weakly coordinating but sometimes, given the conversational context, the most informative utterances we can make are not very informative. 
factory farming causes suffering or that meat production is a significant contributor to climate change. One way to understand these further contributions is to think of them as narrowing down the context of utterance for (2). They provide contextual cues for Ann that enable her to interpret to which proposition Ben is reacting. The previous claims about reasons, for example, should tell her that Ben's utterance in (2) must in some way concern the moral communities to which she belongs the majorities of which are against actions that cause suffering or climate change. That is, by referring to these reasons, Ben can help Ann to understand that he rejected the propositions in the relevant cloud according to which eating meat does not have the natural properties determined by what type of actions are disapproved of by the moral communities that care about pain, suffering, and climate change and of which Ann is a member.

Let me then conclude by summarizing how the previous proposals enables the SRC-views to make sense of the genuine disagreement between Ann and Ben: (i) given the context of utterance and the lack of contextual cues, when Ann utters (1) she can only put into play a cloud of propositions; (ii) by uttering (2) Ben reacts to some of the propositions put into play by outright rejection and so the disagreement is an ordinary first-order factual disagreement; (iii) we can explain to which propositions Ben should react to by considering the action coordinating function of the moral discourse; and (iv) these norms and further exchanges about reasons can help Ann to understand what Ben in fact means.

\section{The Alternatives}

This final section will briefly outline two alternative theories, which the defenders of the SRC-views have already tried to use for making sense of moral disagreements. I will also introduce some of the problems of these proposals and consider how the previous section's proposal can avoid them.

Traditionally, the defenders of the SRC-views have often endorsed the expressivists' disagreement in attitude account 
of moral disagreement. ${ }^{24}$ This proposal grants that Ann's and Ben's assertions (1) and (2) can both be true at the same time because they are about different natural properties. This proposal thus accepts that there need not be a factual disagreement between Ann and Ben. It then, however, notes that Ann and Ben presumably have conflicting attitudes of approval and disapproval towards eating meat. ${ }^{25}$ Ann is, after all, implying that actions of eating meat are not the type of actions against which her own moral code is whereas Ben implies that those actions are the kind of actions against which his own moral code is. Ann and Ben can thus be claimed to have a disagreement in attitude: they have a 'clash of practical attitudes' in the same way in which we can disagree when we have different plans concerning where we are to go for dinner together.

To see why this view is problematic, we must first notice that Ben could express his disagreement with Ann also in the following way (Schroeder 2008: 17):

(9) Ben: What Ann just said is false.

One problem is that, according to the traditional interpretations of the SRC-views, Ben could not make this assertion because the proposition Ann asserted - what she said - is true according to these views. The actions of eating meat can really lack the natural property determined by Ann's own moral code.

In response, Brogaard (2008: 400), Björnsson and Finlay (2010: 20-21), and Finlay (2017: 201) have suggested that, due to the conversational context, the expression 'What Ann just said...' does not here pick out the proposition Ann asserted but rather the proposition which Ben could assert by uttering 'Eating meat is wrong' himself in the

24 Stevenson introduced the account first in his prescriptivist framework (1944: 2-8). In the debates concerning the SRC-views, it has been defended, for example, by Wong (1984 and 2011), Harman (1996), Dreier (1999: 569 and 2009: 106), Jackson (2008: 81-82), Björnsson and Finlay (2010: 27-28), and Finlay (2014).

${ }^{25}$ Finlay (2017: 191) calls this account 'quasi-expressivist' because many defenders of the view suggest that moral utterances pragmatically express the conflicting attitudes. 
context. ${ }^{26}$ However, even if there exists linguistic devices that pick out unasserted propositions in the previous radically context sensitive way, 'What $X$ just said...' does not seem to one of them - at least not in the ordinary nonmoral contexts. ${ }^{27}$ Rather, in these contexts, this expression seems to function uniformly as a device for indirect quotation.

Consider a situation in which Ann utters:

(10) Ann: I was told that Sally stole the money. ${ }^{28}$

In this example, I could use the phrase 'Yes, that's true' to agree with the proposition that Sally stole the money (which was not asserted by Ann). Yet, by saying that 'What she just said is false!' I would only be able to deny that Ann was told that Sally stole the money (i.e., the asserted proposition). In this non-moral context, the reference of this expression just does not switch from the asserted proposition about what Ann was told to the unasserted proposition concerning what Sally has done. This means that defending the SRC-views with the disagreement in attitude strategy requires thinking that expressions such as 'What she just said...' pick out the propositions that are not asserted in the moral contexts and yet asserted propositions in the non-moral contexts. The problem is that this assumption seems ad hoc - it seems that the only motivation for making it would be theory-driven, motivated by an attempt to save the SRCviews from the objection. ${ }^{29}$

In contrast, the proposal described above does not require the previous assumption. It is compatible with the view that 'What she just said...' functions also in the moral

\footnotetext{
${ }^{26}$ As Finlay (2017: 200-201) notes, defenders of the disagreement in attitude view could turn metalinguistic at this point. For problems of this response, see below.

${ }^{27}$ For examples of such devices, see Björnsson and Finlay (2010: 19)

${ }^{28}$ I borrow this example from Björnsson and Finlay (2010: 19).

${ }^{29}$ Perhaps due to this kind of concerns, more recently Finlay (2017: 202) has suggested that we can explain at least some of our intuitions about disagreements away on the basis of semantic opacity - the idea that we, as ordinary speakers, are not aware of the fact that in some cases we can end up talking past one another. For further problems of the view, see Ridge (2013) and Björnsson (2017).
} 
contexts in the standard way as a device for indirect quotation that uniformly picks out the proposition asserted by the previous speaker. It's just that, according to this proposal, at least in the moral contexts the previous speaker puts into a play a whole cloud of propositions and so the new speaker can, in principle, use a sentence beginning with 'What she just said...' to express her agreement or disagreement with any one of these propositions. Thus, one reason for preferring the proposition cloud proposal is that it does not require making any ad hoc assumptions about how certain expressions used to refer to other propositions function.

The second suggestion is that we should understand moral disagreements such as the one between Ann and Ben as metalinguistic negotiations concerning which moral concepts should be adopted. ${ }^{30}$ Many formulations of this proposal rely on the idea that different speakers and communities have different moral concepts, which is not compatible with the kind of Contextualism explored in this chapter. For this reason, I need to reformulate the proposal in a slightly different way.

Let's assume that the character of the moral terms is such that when Ann asserts (1) her assertion is about a certain natural property determined by the moral code of her own moral community. Likewise, when Ben asserts (2) his assertion is about a different natural property determined by the moral code of his moral community. As a consequence, let's assume that there is no first-order factual disagreement between Ann and Ben as they are talking past one another. Yet, intuitively we would think that they disagreed.

Here's how the metalinguistic proposal promises to accommodate that disagreement intuition. One way to understand the character of a moral term is that it is a function from the contexts of use to different natural properties as semantic values. This means that, in the

\footnotetext{
${ }^{30}$ For different variations of the view, see Robinson (2010), Plunkett and Sundell (2013), Khoo and Knobe (2016), Bolinger (ms), and Silk (2016: 128-129 and 2017: 214 and 222-223) even if Silk (2017:225) himself does not classify his view as metalinguistic (for a discussion, see Finlay 2017: 196 fn. 26).
} 
previous example, even if Ann and Ben are talking to one another and so in a loose sense belong to the same conversational context, we should properly speaking think that their utterances are made in different contexts of use. The context of use for Ann's utterance is the moral code of her community, which explains why the semantic value of '... is wrong' in Ann's mouth is a certain natural property. Likewise, the context of use for Ben's utterance is a different moral code - his community's code, which explains why the semantic value of '... is wrong' in his mouth is a different natural property.

The metalinguistic proposal then is that, even if Ann and Ben are literally talking past one another and there is no factual first-order disagreement between them, they can be understood to be disagreeing in a different, nonstandard way. This is because, in the conversation, they are both trying to get their conversational partner to move to the same context of use as they are in themselves. Thus, by asserting (2), Ben is trying to get Ann to join his moral community that is against eating meat so that the context of use for Ann's moral utterances too would become the moral code of his moral community. If Ben were successful, not only would Ann's previous assertion become false but she would also come to adopt the vegetarian moral code of Ben's community, which would effectively co-ordinate her and Ben's actions to not eating meat. As we saw above, this type of action co-ordination can be understood to be the reason why the conversation is taking place in the first place. Likewise, Ann too is, according to this proposal, trying to get Ben to switch over to the context of the moral code of her own moral community, which too would help her to get Ben to coordinate his actions with her meat eating habits.

The problem with this proposal is that it fails to make sense of disagreements in eavesdropping cases. ${ }^{31}$ Consider

31 For a similar objection, see Finlay (2017: 194). One strategy to respond to this concern is to limit the scope of the disagreements to which the account is supposed to apply (see Silk (2017) and Khoo and Knobe (2016: 3)). Yet, this entails that my proposal should be preferred on the grounds of simplicity. According to Finlay, different versions of the metalinguistic proposal also threaten to mislocate the disagreements (192-193), fail to accommodate disagreements between 
the following exchange between Isabel and James who are listening to the conversation between Ann and Ben from a distance:

(11) Isabel: No, Ann is mistaken - eating meat is wrong!

(12) James: You are right - she is mistaken.

Intuitively, here too, Isabel disagrees with Ann. Yet, this disagreement between Isabel and Ann cannot be construed as a metalinguistic negotiation concerning which moral code should be adopted as the shared context of use. The purpose of Isabel's utterance cannot be to get Ann to join the context of Isabel's moral code given that Ann is not even aware of Isabel's existence and so her utterance cannot have any influence on which moral code Ann adopts as the relevant context for her moral utterances. The fact that Isabel disagrees with Ann also cannot be understood as consisting of a metalinguistic negotiation between Isabel and James given that they already know that they both share the same moral code and thus belong to the same context. The metalinguistic proposal thus seems to lack the resources required for dealing with disagreements such as the one between Ann and eavesdropper Isabel.

In contrast, the proposal outlined in $\S 4$ can do better. According to it, Ann's assertion (1) puts into a play a proposition cloud. Her audience can then react to these propositions by either accepting or rejecting them. This is why Isabel can react with rejection to those propositions in play the rejection of which would make a suitably informative contribution to the conversation she is having with her fellow eavesdropper James (see von Fintel and Gillies 2011: 127-129). Thus, Isabel's disagreement with Ann can again be understood as an ordinary first-order factual disagreement - she is flat out rejecting one of the things Ann said. Yet, her rejection of that proposition put into play by Ann can be informative in the conversion she has with James, as it can co-ordinate action and choice. By uttering (11), Isabel can confirm whether she and James 
are on the same page with regards to eating meat and also check whether they would side with the same person in disagreements over meat eating on future occasions.

This means that one advantage of my proposal is that it can accommodate a wider range of disagreement cases than the metalinguistic proposal. In addition to enabling the SRC-views to understand moral disagreements as ordinary first-order factual disagreements and thus in addition to addressing the most common objection to these views, the proposal outlined in $\$ 4$ also therefore does better than the previous proposals. It does not require making any ad hoc assumptions about how certain devices of indirect quotation function in moral contexts and it can also deal with the disagreement cases, which the metalinguistic proposal fails to accommodate. I thus conclude that the proposition cloud account is the most promising alternative for the contextualists.

\section{References:}

Björnsson, Gunnar (2017): 'The Significance of Ethical Disagreement for Theories of Ethical Thought and Talk'. In T. McPherson and D. Plunkett (eds.): The Routledge Handbook of Metaethics (New York: Routledge).

Björnsson, Gunnar and Finlay, Stephen (2010): 'Metaethical Contextualism Defended'. Ethics 121/1: 7-36.

Blackburn, Simon (1993): 'How to Be an Ethical AntiRealist'. In his Essays in Quasi-Realism (Oxford: Oxford University Press), 166-181.

Blackburn, Simon (1998): 'Moral Relativism and Moral Objectivity'. Philosophy and Phenomenological Research 58/1: 195-198.

Bolinger, Renee (ms.): 'Metalinguistic Negotiations in Moral Disagreement'.

Brogaard, Berit (2008): 'Moral Contextualism and Moral Relativism'. Philosophical Quarterly 58/232: 385-409. 
Capps, David, Lynch, Michael and Massey, Daniel (2009):

'A Coherent Moral Relativism'. Synthese 166/2: 413430 .

DeScioli, Peter and Kurzban, Robert (2013): 'A Solution to the Mysteries of Morality'. Psychological Bulletin 139/2: 477-496.

Dowell, Janice (2013): 'Flexible Contextualism about Deontic Modals'. Inquiry 56/2-3: 149-178.

Dreier, James (1990): 'Internalism and Speaker Relativism'. Ethics 101/1: 6-26.

Dreier, James (1999): 'Transforming Expressivism'. Noûs 33/4: 558-572.

Dreier, James (2009): 'Relativism and the Problem of Disagreement'. Philosophical Perspectives 23: 79-110.

Egan, Andy and Weatherson, Brian (eds.) (2011): Epistemic Modality (Oxford: Oxford University Press).

Finlay, Stephen (2014): Confusion of Tongues: A Theory of Normative Language (Oxford: Oxford University Press)

Finlay, Stephen (2016): “Ought': Out of Order'. In N. Charlow and M. Chrisman (eds.): Deontic Modality (Oxford: Oxford University Press), 169-199.

Finlay, Stephen (2017): 'Disagreement Lost and Found'. Oxford Studies in Metaethics 12: 187-205.

Fintel, Kai von and Gillies, Anthony (2011): "Might' Made Right'. In A. Egan and B. Weatherson (eds.): Epistemic Modality (Oxford: Oxford University Press), 108-130.

Grice, H.P. (1975): 'Logic and Conversation'. In P. Cole and J.L. Morgan (eds.): Speech Acts (New York: Academic Press), 41-58.

Hare, R.M. (1952): The Language of Morals (Oxford: Oxford University Press).

Harman, Gilbert (1975): 'Moral Relativism Defended'. Philosophical Review 84/1: 3-22. 
Harman, Gilbert (1996): 'Part 1: Moral Relativism'. In G. Harman and J.J. Thomson's Moral Relativism and Moral Objectivity (Oxford: Blackwell).

Hobbes (2012 [1651]): Leviathan, vols. I-III, ed. by N. Malcolm (Oxford: Oxford University Press).

Jackson, Frank (2008): 'The Argument from the Persistence of Moral Disagreement'. Oxford Studies in Metaethics 3: 75-86.

Joyce, Richard (2006): The Evolution of Morality (Cambridge, MA: MIT Press).

Kaplan, David (1989): 'Demonstratives'. In J. Almog, J. Perry, and H. Wettstein (eds.): Themes from Kaplan (New York: Oxford University Press), 481-563.

Khoo, Justin and Knobe, Joshua (2016): 'Moral Disagreement and Moral Semantics'. Noûs DOI: 10.1111/nous.12151.

Kolodny, Niko and MacFarlane, John (2010): 'Ifs and Oughts'. The Journal of Philosophy 107/3: 115-143.

Kratzer, Angelika (1977): 'What 'Must' and 'Can' Must and Can Mean'. Linguistics and Philosophy 1/3: 337355.

Kratzer, Angelika (1981): 'The Notational Category of Modality'. In H. Eikmeyer and H. Rieser (eds.): Words, Worlds, and Contexts (Berlin: de Gruyter), 3874 .

Kratzer, Angelika (1991): 'Modality'. In A. Stechow and D. Wunderlich (eds.): Semantics: An International Handbook of Contemporary Research (Berlin: de Gruyter), 639-650.

Lewis, David (1973): Counterfactuals (Oxford: Blackwell).

MacFarlane, John (2010): 'Epistemic Modals: Relativism vs. Cloudy Contextualism'. MS, Chambers Philosophy Conference on Epistemic Modals, University of Nebraska. 
Montaigne, Michel de (1958 [1572-1574]): 'Of Custom, and not Easily Changing an Accepted Law'. In M. Frame (ed.): The Complete Essays of Montaigne (Stanford: Stanford University Press), 77-89.

Moore, G.E. (1912): Ethics (Oxford: Oxford University Press).

Plunkett, David and Sundell, Tim (2013): 'Disagreement and the Semantics of Normative and Evaluative Terms'. Philosophers' Imprint 13/23: 1-37.

Prichard, H.A. (1932): 'Duty and Ignorance of Fact'. Proceedings of the British Academy 18: 67-92.

Rawls, John (1971): A Theory of Justice (Cambridge, MA: Harvard University Press.

Ridge, Michael (2013): 'Disagreement'. Philosophy and Phenomenological Research 86/1: 41-63.

Robinson, Denis (2010): 'Reflections on Moral Disagreement, Relativism, and Skepticism about Rules'. Philosophical Topics 38/2: 131-156.

Schroeder, Mark (2008): Being For (Oxford: Oxford University Press).

Shafer-Landau, Russ (2004): Whatever Happened to Good and Evil? (Oxford: Oxford University Press).

Shafer-Landau, Russ (2010): The Fundamentals of Ethics (Oxford: Oxford University Press).

Silk, Alex (2014): 'Evidence Sensitivity in Weak Necessity Modals'. The Journal of Philosophical Logic 43/3: 691723.

Silk, Alex (2016): Discourse Contextualism: A Framework for Contextualist Semantics and Pragmatics (Oxford: Oxford University Press).

Silk, Alex (2017): 'Normative Language in Context'. Oxford Studies in Metaethics 12: 206-243.

Stevenson, Charles (1944): Ethics and Language (New Haven: Yale University Press). 
Sumner, William (1906): Folkways (Boston: Ginn and Company).

Williams, Bernard (1979): 'Internal and External Reasons'. In R. Harrison (ed.): Rational Action (Cambridge: Cambridge University Press), 101-113.

Wong, David (1984): Moral Relativity (Los Angeles: University of California Press).

Wong, David (2011): 'Relativist Explanation of Interpersonal and Group Disagreement'. In S. Hales (ed.): A Companion to Relativism (Malden, MA: Wiley-Blackwell), 411-429. 